International Journal of Child, Youth and Family Studies (2015) 6(3): 353-357

\title{
INTRODUCING FICE (FÉDÉRATION INTERNATIONALE DES COMMUNAUTÉS EDUCATIVES)
}

\author{
David C. Lane
}

David C. Lane is Honorary Life President, FICE-International, Wakefield, United Kingdom. E-mail: dcl@DavidLane.org

\section{What is FICE?}

The development of FICE provides a fascinating window on the way that politics, economics, and social conditions have changed over the 70 years since the end of the Second World War. In a brief Foreword it is only possible to describe trends and give selective examples, and no offence is intended to National Sections, Presidents, and other FICE officers who are not mentioned by name. For a full history of FICE see Children, Families and Care: reflections on the first sixty years of FICE by Robert Shaw (Shaw, 2008).

When FICE was founded, many countries had suffered major devastation, and, as always, children and young people were some of the main casualties of the conflict, through personal injury, loss of family members, or the trauma of their experiences. Millions were displaced, orphaned, or separated from their families, and all sorts of systems, including children's villages, were set up to cope with the large numbers of needy, often disturbed, children. How were the professionals who had to care for these children to cope with their problems? One way was to share thinking and provide support through international links, and this led to the founding in 1948 of FICE.

For those who do not know of FICE (usually pronounced fee-say), it is an international professional association for those who work with children, young people, and their families. At its foundation the letters stood for the Fédération Internationale des Communautés d'Enfants (in French), but by 1982 this description was inadequate for the range of services provided by members, and the name was changed to Fédération Internationale des Communautés Educatives (in English International Federation of Educative Communities), broadening the remit but carefully preserving the initials.

FICE's sister organisation, AIEJI, (now referred to as the International Association of Social Educators) was formally created in 1951 in the French sector of Western Germany, to focus on social education/pedagogy. FICE's focus has been primarily on extra-familial care the ways that children and young people are looked after when their own families can no longer care for them. It has therefore at times been viewed as an organisation focusing on residential child care, but its remit has always been broader, and it has always been flexible in accepting new ideas while at the same time continuing to champion quality residential care for children. 


\section{Changing challenges}

The Second World War may now seem a long time ago, but throughout the years since its end, new challenges have continually come forward for people working with children and young people, and FICE has continually helped its members to find ways of creating innovations and combating problems.

Throughout FICE's early years the Cold War dominated European politics. Despite this, representatives from many Eastern European countries continued to attend FICE events, with the child care professionals often accompanied by their political minders. Despite the strictures, a dialogue was maintained, and in 1987 FICE was awarded the title of Peace Messenger by the United Nations in recognition of the hard work put in by delegates from both sides of the Iron Curtain.

In the 1990s conflict in the former Yugoslavia caused major disruption and loss of life. In the aftermath, FICE again took up its role of Peace Messenger, organising camps for young people from the new countries to come together, learn about each other, and make friends, hopefully helping to overcome the bitterness and tensions caused by the fighting.

More recently there have been problems such as the growth of substance abuse, child trafficking, greater awareness of the sexual abuse of children, refugee children, unaccompanied minors, and the challenges posed by the Internet.

\section{How FICE works}

FICE was originally set up under the auspices of the United Nations Educational, Scientific and Cultural Organisation (UNESCO), which provided the initial funding for the organisation. However, no long-term funds were made available after the criteria for funding had been tightened at the Third UNESCO Conference in Beirut in 1948. Among the criteria for receiving funding was the existence of National Sections. These were created through the Statutes adopted at the 1950 FICE Congress in Lyons.

FICE was the victim of both opposition and misunderstanding and, though it received some grants from UNESCO, it did not gain regular funding until FICE was given consultative status in 1954. UNESCO provided modest core funding for 30 years, but following the withdrawal from UNESCO of the United States in 1984 and the United Kingdom in 1985 resources were targeted on developing countries and FICE lost its grant. Until 1998 the Pestalozzi Foundation provided a secretariat and some funding but this was tapered off. FICE International was also able to obtain some funding for special projects from the European Union but has often had to rely on personal donations, grants, membership fees, congresses, and projects.

The prime movers when FICE held its first conference at Trogen in Switzerland were Elizabeth Rotten and Bernard Drzewieski. For many years, FICE's President was René de Cooman and French was the dominant language. In 1970 the statutes were changed to limit the term of office of the President to three terms of two years each and Louis François, who had first come into contact with the founders of FICE as a School Inspector and had remained in close touch with the organisation, became President. 
For the last quarter of the 20th century, German-speaking countries took a stronger role with Professor Tuggener from Switzerland as President and the Pestalozzi Foundation funded Franz Züsli as General Secretary. When Thomas Mächler took over the Pestalozzi role, he became FICE Secretary General, working with Dr. Steen Lasson of Denmark and Robert Soisson of Luxembourg as successive Presidents. These were the first Presidents whose mother tongue was not one of the three FICE languages. Dr. Steen Lasson, supported first by Franz Züsli and then by Thomas Mächler, embarked on a programme of encouraging lapsed members to rejoin, encouraging eastern European countries to continue or join after the fall of the Berlin Wall, and seeking new members in, for example, Japan and South Africa to join. The latter initiative ultimately led to the first FICE Congress in any African country.

Robert Soisson, while continuing in Dr. Steen Lasson's footsteps, put more emphasis on updating the constitution and strengthening contacts with European and International organisations including the European Union and UNICEF.

The Dutch took the lead at the start of the 21st century when Theo Binnendijk was President and the office was in Amsterdam. Under Monika Niederle's Presidency the administrative base shifted to Austria, with Andrew Hosie of Scotland as Secretary General. He has been succeeded by Bettina Terp of Austria. Currently, the administrative office and the President, Dashenka (Dasha) Kraleva, are from Bulgaria, based in Sofia.

In recent decades, the Presidents and Secretaries General have been supported by successive Treasurers, Richard Joubert of France and Rolf Widmer of Switzerland, and by a number of Vice-Presidents, who have often taken on specific responsibilities, such as Anton Tobé of the Netherlands, who supported new National Sections in South-Eastern Europe, Martti Kemppainen of Finland, who worked with Russia and the Baltic states, and Søren Hegstrup of Denmark and Dr. Emmanuel Grupper of Israel, who have edited publications such as this special issue of the IJCYFS.

The strength of FICE over the years has lain in the National Sections who comprise the Federal Council. Most of these are from Europe and, over the years, almost every country in Europe has been represented, though the strongest National Sections providing the most consistent support have been those of Austria, Denmark, France, Germany, the Netherlands, and Switzerland. Other countries outside Europe have also played significant roles, such as Canada, Israel, South Africa, and the United States, but attempts to expand further across the world have had limited success.

From the start FICE has worked in three official languages - English, French, and German - and meetings and congresses were interpreted. Depending upon the dominant group at the time, these languages took their turns as the main medium, but increasingly in recent years, English has become the standard language, reflecting changes in other aspects of international communication. FICE has been fortunate in having long-serving interpreters, Helga Stefanov and Christine Karner, who have become well acquainted with the terminology and concepts used in the care of children and young people, and have provided continuity by staying with the organisation longer than any of the serving officers.

The National Sections that make up FICE have, of course, been varied, reflecting the sizes, cultures, and economies of their respective countries. Luxembourg, for example, is very small but comparatively wealthy, and it has always had an active organisation, known as ANCE. Germany has perhaps had the most consistently influential and best-organised 
association. By contrast, a number of individual Americans and Canadians such as Carol Kelly and Jim Anglin have played significant roles in FICE internationally, but their respective political systems of states and provinces has made it difficult to set up a North American network. In some countries, individuals have attended to maintain contact with the international scene; in others, professional associations have acted as the FICE National Section while some government agencies or "quangos" (quasi-governmental societies) have fulfilled the role. In the earlier years special arrangements were often made to fund the attendance of delegates from Eastern Europe, and this remains a problem for those who wish to participate from weak currency countries.

These examples are only given to show the diversity of membership, and the structure of FICE has had to accommodate these differences. It is encouraging that at any one time there have been perhaps 30 or 40 countries in which FICE has been active. As in any organisation, FICE has had its highs and lows. On occasion it has seemed as if it would break up or come to an end, but individuals and associations have always come forward to renew its programmes of activities, maintaining the same aims and values, thus demonstrating that FICE is fulfilling a real ongoing need.

\section{FICE's strengths}

FICE has never been a rich organisation, perhaps reflecting the status of the professions involved (mainly social work and child and youth care/social pedagogy) and services for children. While some National Sections have made major financial contributions to events and projects, FICE has essentially relied upon a massive amount of voluntary support, with members giving of their time and personal resources to participate. Why should they do this? Because of FICE's strengths; here are six:

- Travelling to congresses and Federal Council meetings in other countries, members have come across new ideas, which they have been able to translate into their own countries, perhaps adapted to changing circumstances. The latest plan is to introduce the South African model of ISIBINDI safe play parks into Syria for the thousands of traumatised displaced children there.

- Sometimes, it may not be a matter of picking up new ideas, but of realising that professionals in other countries do things differently, with different ranges of concepts. It is only recently, for example, that social education/pedagogy has been introduced into the United Kingdom, and U.K. delegates for many years found social pedagogical thinking a stimulus and challenge.

- FICE has organised international congresses since its inception. There have been 48 major congresses, as well as numerous expert seminars, such as the series run by the AlpsRhine Group in the 1990s. Attended by several hundred delegates, these congresses have provided major opportunities to network and meet people (sometimes from one's own country!).

- FICE has published a large number of books over the years, in various languages. The main official publications have appeared in English, French, and German, but the National Sections have of course put out their journals and books in their national languages. For many years in the 1990s, FICE also published a Bulletin, mainly edited first by Meir Gottesman from Israel and later by Robert Soisson from Luxembourg. FICE currently has an 
Editorial Board, and this publication is part of a long tradition of sharing good professional thinking and best practices.

- FICE has provided the opportunity for people to come together in partnerships and set up projects of all sorts - visits to each others' countries, placements for students, work in areas of great need such as Romania after the fall of the Ceausescus, exchange trips for children and young people, or working parties on issues such as the drafting of the Malmö Declaration in 1986, or the approval of an International Code of Ethics for child and youth care workers in 1997. Some projects have been initiated by the Federal Council, but most have been devised by partnerships between National Sections, sometimes as equals and sometimes with one better resourced National Section helping another. There are too many examples to list here, and I apologise if I have failed to mention one that a reader considers an important historical milestone.

- Last but not least, meeting other delegates twice a year at the Federal Council meetings over the decades has provided the opportunity to develop not only working partnerships between colleagues but also friendships. This is important not only because of the personal enjoyment of meeting acquaintances time and again, but also because of the trust it engenders between individuals and countries. Those of us who were present when Meir Gottesman, an outstanding long-term Israeli delegate, retired will not forget his gracious speech in which he mentioned how he valued his friendship with Gerhard Haag, the distinguished German representative, despite having lost many of his family in the extermination camps. Such friendship is invaluable in helping the human spirit overcome the horrors of history and build towards international peace.

\section{In Conclusion}

By comparison with many other international bodies, FICE is modest in size and financial resources, but its impact over the last seven decades has been considerable, and its influence has been visible in many countries. The U.N. title of Peace Messenger was well earned, and today's FICE is continuing on the same track.

FICE is still developing, maintaining its original vision and purpose, trying to extend its network and create new contacts. In the last two years, FICE National Sections have been created in Kenya and Ethiopia, and eventually a regional African FICE platform will be the next step, together with South Africa. In Latin America, a National Section has been created in Brazil. In Europe the Ukraine National Section was recently created. In Australia a new member has joined, extending the FICE network to this part of the globe. Contact has also been established with Japanese professionals involved with residential care with a view to creating a Japanese FICE National Section in the near future.

This publication is yet another useful addition to the many books and bulletins which FICE has published over the years, and it demonstrates that FICE is still moving forward, with new creative ideas to improve the quality of services for children and young people.

\section{Reference}

Shaw, R. (2008). Children, families and care: reflections on the first sixty years of FICE. Stoke-on-Trent, UK: Trentham Books. 